\title{
Arrangements of the intravenous parallel infusions with anti- reflux valves decreasing occlusion alarm delay
}

\author{
Han Bum Joe, Bong-Ki Moon, Yeon-Ju Lee, and Sang-Kee Min \\ Department of Anesthesiology and Pain Medicine, Ajou University School of Medicine, Suwon, Korea
}

Background: The methods of arrangement of combined intravenous parallel infusions using anti-reflux valve (ARV), with and without anti-syphon valve (ASV) that could decrease occlusion alarm delay were investigated.

Methods: Occlusion challenge tests were mainly performed as bench experiments of four kinds of multiple parallel infusions (10 ml/h and $50 \mathrm{ml} / \mathrm{h}$ infusions), which were connected at the proximal or distal portion of ARV, with or without ASV. Alarm threshold was set to $1000 \mathrm{mmHg}$. Occlusion alarm delays and the compliances of the infusion systems were compared among groups.

Results: Without ASV, compared to $10 \mathrm{ml} / \mathrm{h}$ infusion alone distal to anti-reflux valve, $50 \mathrm{ml} / \mathrm{h}$ infusion distal to antireflux valve reduced the mean alarm delay from $416 \pm 7 \mathrm{~s}$ to $81 \pm 3 \mathrm{~s}(\mathrm{P}<0.001)$. Compared to $50 \mathrm{ml} / \mathrm{h}$ infusion alone, combined $10 \mathrm{ml} / \mathrm{h}$ and $50 \mathrm{ml} / \mathrm{h}$ infusion distal to ARV prolonged the alarm delay from $81 \pm 3 \mathrm{~s}$ to $133 \pm 6 \mathrm{~s}(\mathrm{P}<0.001)$. However, combined infusions distal to ARV with ASV significantly reduced the alarm delay from $133 \pm 6 \mathrm{~s}$ to $74 \pm 5 \mathrm{~s}$ $(\mathrm{P}<0.001)$, and also reduced the compliance of the infusion system from $2.31 \pm 0.12$ to $1.20 \pm 0.08 \mu \mathrm{l} / \mathrm{mmHg}(\mathrm{P}<0.001)$. Conclusions: The infusion setup of faster infusion rate, lower compliant system using ASV could effectively decrease occlusion alarm delay during multiple intravenous parallel infusions using ARV. (Korean J Anesthesiol 2014; 66: 300-305)

Key Words: Anesthetics, Equipment safety, Intravenous infusion.

\section{Introduction}

During the multiple parallel infusions of intravenous agents, one of the rationales of the recommended use of one-way valve is to prepare a portion anticipated to be closed, in advance for a potential occlusion during the infusion of intravenous agents. Various nomenclatures are used for one-way valve including anti-reflux valve (ARV), back-check valve, pressure-activated valve, non-return valve, and unidirectional valve. ARV must be normally closed at resting state to prevent backflow at the minimal flow rate. ARV is classified according to its crack pressure. Low-crack ARV is used for gravity infusion, and is simply called ARV. High-crack ARV is used for the infusion using syringe pumps, and is called as anti-siphon valve (ASV).

Recently, total intravenous anesthesia has become a rather common practice. Multiple intravenous infusions are concomi-

Received: September 2, 2013. Revised: 1st, October 9, 2013; 2nd, November 11, 2013. Accepted: November 14, 2013.

Corresponding author: Sang-Kee Min, M.D., Department of Anesthesiology and Pain Medicine, Ajou University School of Medicine, San 5, Woncheon-dong, Paldal-gu, Suwon 442-721, Korea. Tel: 82-31-219-5748, Fax: 82-31-219-5579, E-mail: anesmin@nate.com

(c) This is an open-access article distributed under the terms of the Creative Commons Attribution Non-Commercial License (http:// creativecommons.org/licenses/by-nc/3.0/), which permits unrestricted non-commercial use, distribution, and reproduction in any medium, provided the original work is properly cited. 
tantly administered with gravity line. Many clinicians are realizing the advantage of ARV. But, on reflection, it does not seem that ARV has been used in every infusion in the clinical setting. Especially, clinicians may remain unaware of the proper instruction of ARV and the mechanism of triggering alarm, and overestimate the alarm function as it occurs for granted. Furthermore, it was difficult to find a firm standard for the use of ARV and ASV with multi-line infusions.

As a risk reduction aligned with potential occlusion, we investigated the methods of arrangement of multiple parallel infusions and ARV, with and without ASV, decreasing occlusion alarm delay. In addition, we also attempted to find out the method of predicting an alarm delay, and evaluated its effectiveness.

\section{Materials and Methods}

This study was performed in two parts. The first part was collection of infusion data in clinical settings. The second part was occlusion challenge test as bench experiments.

After approval of the institutional review board and written informed consent from patients, the data of the syringe driving pressure were collected from 60 patients who underwent gynecologic surgery using total intravenous anesthesia (TIVA). TIVA was provided using target-controlled infusions (TCI) of $50 \mu \mathrm{g} / \mathrm{ml}$ remifentanil (Ultiva ${ }^{\mathrm{TM}}$, GlaxoSmithKline, Rixensart, Belgium) diluent and 1.0\% propofol (Fresofol ${ }^{\circledR}$, Fresenius Kabi, Germany). Each TCI infusion system was provided with the Orchestra ${ }^{\circledR}$ TCI workstations (Fresenius Vial, Le Grand Chemin, Brezins, France) using the corresponding pharmacokinetic/ pharmacodynamic model of remifentanil [1] and propofol [2,3], and BD Plastipak compatible $60 \mathrm{ml}$ syringes (BD $60 \mathrm{ml}$ Syringe, Luer-Lok $^{\mathrm{TM}}$ Tip, BD, Franklin Lakes, NJ, USA), and low-compliant $200 \mathrm{~cm}$ syringe infusion lines (Injectomat Line ${ }^{\circledR}$, Fresenius Kabi AG, Bad Homburg, Germany). All syringe pumps were calibrated by qualified personnel before the commencement of this study. Zero calibration was $6 \mathrm{~V}$ (error range: $0.05 \mathrm{~V}$ ) and pressure calibration was 0.8 bar. Both TCI infusions were connected at the distal portion of ARV (Ace-Medical Inc, Seoul, Korea). The average opening pressure of this low-crack ARV was $5.3 \mathrm{mmHg}$ (approximately $7 \mathrm{mbar}$ ). Patients were randomly allocated into the two groups concerning ASV (Ace-Medical Inc, Seoul, Korea) at the end of the syringe infusion lines or not. The average opening pressure of ASV was $113 \mathrm{mmHg}$ (approximately 150 mbar). The average tolerable backpressures which were informed by the manufacturer was $2250 \mathrm{mmHg}$ (= $3000 \mathrm{mbar}$ ). Anesthesia were induced targeting effect-site concentration of 5.4 $\mu \mathrm{g} / \mathrm{ml}$ of propofol and $4.0 \mathrm{ng} / \mathrm{ml}$ of remifentanil, and propofol/ remifentanil TCIs were titrated to maintain the bispectral index between 40 and 60 , and systolic blood pressure and heart rate as $\pm 20 \%$ of baseline values. The maximal syringe driving pressures $\left(\mathrm{P}_{\max }\right)$ at the period of initial bolus, and the maintaining pressure at 30 min after the start of infusion $\left(\mathrm{P}_{30 \mathrm{~min}}\right)$ were recorded.

Occlusion challenge test was performed as a bench experiment. Schematic diagrams of the four kinds of setups are illustrated in Fig. 1. Infusion bag was placed $1 \mathrm{~m}$ above the infusion assembly and the dropping rate was maintained about $100 \mathrm{ml} /$ $\mathrm{h}$ using intravenous regulator set (Auto-Flow ${ }^{\circledR}$, Ace-Medical Inc, Seoul, Korea). Main infusion assemblies were made with four three-way stopcocks and ARV with or without ASV. The infusion bag was connected to the first stopcock using an infusion set. An in-line type low-crack ARV (Ace-Medical Inc, Seoul, Korea) was inserted between the first and the second stopcock. This low-crack ARV was same as that used in clinical study above. The infusion assembly was made in a water bath to remove air. Each infusion system was composed of a $60 \mathrm{ml}$ syringe, syringe pump, and syringe infusion lines identical with those used in the clinical study described above. Three syringe pumps were randomly used. Each syringe and infusion line was

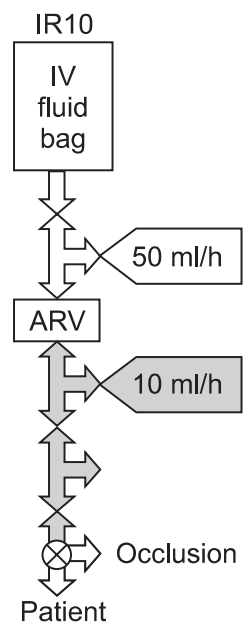

www.ekja.org
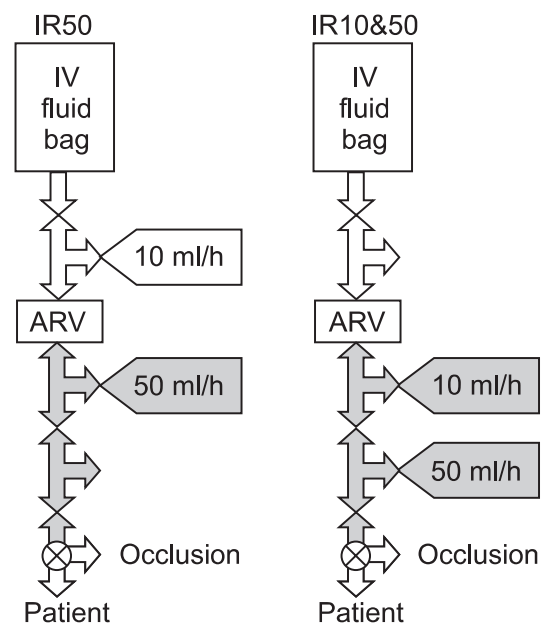

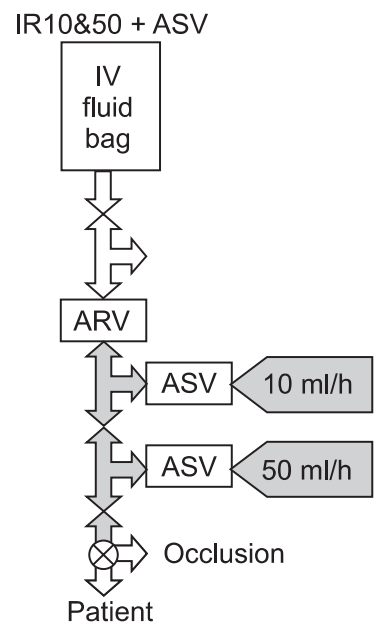

Fig. 1. Four kinds of setups for the multiple parallel infusions of $10 \mathrm{ml} / \mathrm{h}$ and $50 \mathrm{ml} / \mathrm{h}$ using anti-reflux valve (ARV) with or without anti-syphon valve (ASV) for occlusion challenge test. The $10 \mathrm{ml} / \mathrm{h}$ infusion alone was connected distal to ARV (IR10), and the $50 \mathrm{ml} / \mathrm{h}$ infusion alone distal to ARV (IR50), and both 10 and $50 \mathrm{ml} / \mathrm{h}$ infusions distal to ARV (IR10\&50), and both 10 and $50 \mathrm{ml} /$ h infusions distal to ARV using ASV $($ IR10\&50 + ASV). The gray portion indicates the portion anticipated to be closed after occlusion. 
used only for a single occlusion challenge. ARV was commonly used in every setup, and each infusion system of $10 \mathrm{ml} / \mathrm{h}$ and 50 $\mathrm{ml} / \mathrm{h}$ was connected to one of the first, second, and third stopcocks of the infusion assembly, with or without ASV. Infusion rate of $10 \mathrm{ml} / \mathrm{h}$ was chosen to simulate the remifentanil TCI of $50 \mu \mathrm{g} / \mathrm{ml}$ diluent, and $50 \mathrm{ml} / \mathrm{h}$ of infusion to $1 \%$ propofol TCI. Forty eight occlusion challenges were randomly allocated into one of the four setups, IR10, IR50, IR10\&50, and IR10\&50+ ASV, respectively. In the setup of IR10, the $10 \mathrm{ml} / \mathrm{h}$ infusion was connected distal to ARV while connecting the $50 \mathrm{ml} / \mathrm{h}$ infusion proximal to ARV. In the setup of IR50, the $50 \mathrm{ml} / \mathrm{h}$ infusion was connected distal to ARV while connecting the $10 \mathrm{ml} / \mathrm{h}$ infusion proximal to ARV. In the setups of combined infusions, both 10 $\mathrm{ml} / \mathrm{h}$ and $50 \mathrm{ml} / \mathrm{h}$ infusions were connected distal to ARV, without ASV (IR10\&50) or with ASV (IR10\&50 + ASV). Occlusion alarm threshold $\left(\mathrm{P}_{\text {set }}\right)$ was set to $1000 \mathrm{mmHg}$. Before the start of infusion, $2 \mathrm{ml}$ of infusate was evacuated to the atmosphere while pressing the purge button to prevent the start-up delay [4,5]. After obtaining steady state infusion of each pump (longer than $5 \mathrm{~min}$ ), the occlusion challenge was performed. This was done by closing the fourth stopcock at the moment when the residual volume in the syringes was between 40 to $30 \mathrm{ml}$. During the study, the display panel of pump had been switched to the pressure-monitoring window, and the changes of the syringe driving pressure were recorded into video-files until one of the pumps triggered an alarm. The gray portions of Fig. 1 indicate the portion anticipated to be closed after the distal occlusion.

Baseline syringe driving pressure $\left(\mathrm{P}_{0}\right)$ before occlusion, and occlusion alarm delay $\left(\mathrm{T}_{\mathrm{m}}\right)$ from the time of occlusion to the time of occlusion alarm triggered at the one of the syringe pumps, were measured and compared between the setups. To calculate the compliance of each infusion setup, linear regression analysis was performed between the pressure and the volume using Sigmaplot ${ }^{\circledR}$ for Windows version 10.0 (Systat Software, San Diego, CA, USA). The compliance $(\mu \mathrm{l} / \mathrm{mmHg})$ of the infusion setup was defined as the coefficient for slope ( $\Delta$ volume/ $\Delta$ pressure) of each regression line, which was compared among the four setups. As a post-hoc study, the predicted alarm delay $\left(\mathrm{T}_{\mathrm{p}}\right)$ was calculated using Equation 1 with $1000 \mathrm{mmHg}$ of $\mathrm{P}_{\text {set, }}$, the compliance $(\mathrm{C})$ and infusion rate $(\mathrm{IR}, \mathrm{ml} / \mathrm{h})$. Digits in the equation (e.g. 3600, 1000) were used for the conversions of time unit (hour into second) and volume unit ( $\mathrm{ml}$ to $\mu \mathrm{l}$ ). Then $\mathrm{T}_{\mathrm{p}}$ was compared with $\mathrm{T}_{\mathrm{m}}$ in each setup, respectively.

$$
\mathrm{T}_{\mathrm{p}}=\left(\mathrm{P}_{\text {set }}-\mathrm{P}_{\mathrm{o}}\right) \times \frac{3600 \times \sum_{i=1}^{n} C_{i}}{1000 \times \sum_{i=1}^{n} I R_{i}}
$$

Data are expressed as mean $\pm \mathrm{SD}$. Comparisons of the variables between four setups were performed using an ANOVA, and post-hoc analyses were carried out using Scheffe's adjustment. Continuous variable between $\mathrm{T}_{\mathrm{m}}$ and $\mathrm{T}_{\mathrm{p}}$ were compared using an independent t-test. $\mathrm{P}<0.05$ was considered significant. Statistical calculations were performed using SPSS 13.0 for windows (SPSS, Chicago, IL, USA).

\section{Results}

The clinical infusion data of $\mathrm{P}_{\max }$, and $\mathrm{P}_{30 \min }$ during TCI are summarized in Table 1. During TCI, compared to the infusion without ASV, the infusions with ASV showed significant higher syringe driving pressures during the bolus infusion and at the maintenance period. The maximum $\mathrm{P}_{\max }$ during remifentanil TCI with ASV showed to increase up to $360 \mathrm{mmHg}$, and propofol TCI with ASV have shown the highest $\mathrm{P}_{\max }(=750 \mathrm{mmHg})$, when the syringe pump infusing larger than $10 \mathrm{ml}$ of propofol over $30 \mathrm{~s}$ with its maximal infusion rate of $1200 \mathrm{ml} / \mathrm{h}$.

Occlusion challenge tests showed higher $\mathrm{P}_{0}$ in IR10\&50 + ASV before occlusion (Table 2). After occlusion challenge, alarms were triggered at the syringe pumps of the $10 \mathrm{ml} / \mathrm{h}$ infusion in IR10, but were triggered at the $50 \mathrm{ml} / \mathrm{h}$ infusion in other setups. $\mathrm{T}_{\mathrm{m}}$ of IR10 was nearly 5 times longer than that of IR50 after occlusion (Table 2), and $\mathrm{T}_{\mathrm{m}}$ of IR10\&50 was significantly prolonged than that of IR50. However, in IR10\&50 + ASV, $T_{m}$ was significantly shorter than IR10\&50. Fig. 2 presents the relationship between the syringe driving pressure and the infused volume. The regression analysis for the compliance showed high linearity (mean Adjusted $\mathrm{R}_{\mathrm{sqr}}=0.9997$ ). The compliances between IR10, IR50, and IR10\&50 + ASV were not different between groups $(\mathrm{P}=0.471,0.403,0.999)$. However, IR10\&50 showed a higher

Table 1. The Maximal Syringe Driving Pressures $\left(\mathrm{P}_{\max }\right)$ at the Period of Initial Bolus, and the Maintaining Pressure at 30 min $\left(\mathrm{P}_{30 \mathrm{~min}}\right)$ after the Start of Infusion during the Target-controlled Infusion of $50 \mu \mathrm{g} / \mathrm{ml}$ of Remifentanil Diluent and 1.0\% Propofol, with and without Anti-syphon Valve (ASV)

\begin{tabular}{|c|c|c|c|c|c|c|}
\hline & \multicolumn{2}{|c|}{$50 \mu \mathrm{g} / \mathrm{ml}$ remifentanil } & \multirow[b]{2}{*}{$P$ value } & \multicolumn{2}{|c|}{$1.0 \%$ propofol } & \multirow[b]{2}{*}{$P$ value } \\
\hline & $\begin{array}{l}\text { Without ASV } \\
\quad(\mathrm{n}=30)\end{array}$ & $\begin{array}{l}\text { With ASV } \\
(\mathrm{n}=30)\end{array}$ & & $\begin{array}{l}\text { Without ASV } \\
\quad(\mathrm{n}=30)\end{array}$ & $\begin{array}{l}\text { With ASV } \\
(\mathrm{n}=30)\end{array}$ & \\
\hline $\mathrm{P}_{\max }(\mathrm{mmHg})$ & $144 \pm 42$ & $266 \pm 40$ & $<0.001$ & $467 \pm 49$ & $630 \pm 62$ & $<0.001$ \\
\hline $\mathrm{P}_{30 \min }(\mathrm{mmHg})$ & $65 \pm 31$ & $155 \pm 51$ & $<0.001$ & $100 \pm 47$ & $225 \pm 63$ & $<0.001$ \\
\hline
\end{tabular}

Data are mean \pm SD. 
Table 2. Baseline Syringe Driving Pressure $\left(\mathrm{P}_{0}\right)$ before Occlusion Challenge during the Multiple Parallel Infusions of $10 \mathrm{ml} / \mathrm{h}$ and $50 \mathrm{ml} / \mathrm{h}$ Using Antireflux Valve (ARV)

\begin{tabular}{|c|c|c|c|c|}
\hline & $\begin{array}{c}\text { IR10 } \\
(\mathrm{n}=12)\end{array}$ & $\begin{array}{c}\text { IR50 } \\
(\mathrm{n}=12)\end{array}$ & $\begin{array}{l}\text { IR10\&50 } \\
(\mathrm{n}=12)\end{array}$ & $\begin{array}{c}\text { IR10\&50+ASV } \\
(\mathrm{n}=12)\end{array}$ \\
\hline $\mathrm{P}_{0}(\mathrm{mmHg})$ & $20 \pm 3$ & $20 \pm 3$ & $19 \pm 6$ & $145 \pm 10^{*}$ \\
\hline $\mathrm{T}_{\mathrm{m}}(\mathrm{s})$ & $416 \pm 7$ & $81 \pm 3^{+}$ & $133 \pm 6$ & $74 \pm 5^{*}$ \\
\hline $\mathrm{T}_{\mathrm{p}}(\mathrm{s})$ & $420 \pm 7$ & $82 \pm 3$ & $134 \pm 7$ & $74 \pm 5$ \\
\hline Compliance $(\mu \mathrm{l} / \mathrm{mmHg})$ & $1.19 \pm 0.02$ & $1.14 \pm 0.04$ & $2.31 \pm 0.12 *$ & $1.20 \pm 0.08$ \\
\hline
\end{tabular}

Data are mean $\pm \mathrm{SD}$. The $10 \mathrm{ml} / \mathrm{h}$ infusion alone (IR10), and the $50 \mathrm{ml} / \mathrm{h}$ infusion alone (IR50) was connected distal to ARV, and both 10 and $50 \mathrm{ml} / \mathrm{h}$ infusions distal to ARV (IR10\&50), and with anti-syphon valve (IR10\&50 + ASV). The occlusion alarm delay $\left(\mathrm{T}_{\mathrm{m}}\right)$ was measured, and alarm delay was predicted $\left(\mathrm{T}_{\mathrm{p}}\right.$ ) using compliance. ${ }^{*} \mathrm{P}<0.001$ vs. other groups, ${ }^{\dagger} \mathrm{P}<0.001 \mathrm{vs}$. IR10 and IR10\&50.

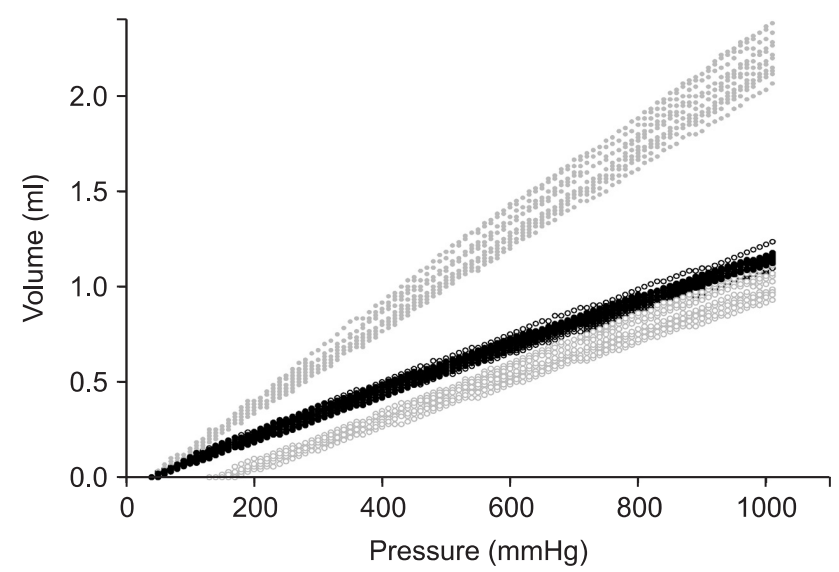

Fig. 2. Scatter plots of the relationship between the syringe driving pressure and the infused volume after occlusion of the multiple parallel infusions of $10 \mathrm{ml} / \mathrm{h}$ and $50 \mathrm{ml} / \mathrm{h}$ using anti-reflux valve (ARV). The 10 $\mathrm{ml} / \mathrm{h}$ infusion alone was connected distal to ARV (black dot, $\bullet$ ), and the $50 \mathrm{ml} / \mathrm{h}$ infusion alone distal to ARV (black blank, O), and both 10 and $50 \mathrm{ml} / \mathrm{h}$ infusions distal to ARV (gray dot, $\bullet$ ), and both 10 and 50 $\mathrm{ml} / \mathrm{h}$ infusions distal to ARV using anti-siphon valve (gray blank, O).

compliance than the other setups. The calculated $\mathrm{T}_{\mathrm{p}}$ were not different to $\mathrm{T}_{\mathrm{m}}$ within each setup $(\mathrm{P}=0.176,0.580,0.780$, and 0.639 , respectively).

\section{Discussion}

Multiple parallel infusions of different infusion rates using ARV showed different degrees of occlusion alarm delay according to their arrangements. After occlusion, the closed portions consisted of the infusion systems of faster infusion rate and lower compliance could effectively decrease occlusion alarm delay, especially using ASV.

To trigger alarm after occlusion, an anticipating portion to be closed must exist. This essential space could be created using low-crack ARV in the middle of the infusion line. After occlusion, the intra-luminal pressure within this portion will be raised, and occlusion alarm will be finally triggered when the syringe driving pressure reaches the pressure of alarm threshold.
However, the occlusion alarm is always delayed, because the pressure setting for occlusion alarm threshold must be set relatively higher than the infusing driving pressure, and a disposable syringe has a compliant structure of the rubber bulb to prevent leakage from the hollow barrel during injection.

Single faster infusion arranged at the distal portion separated by ARV from the slower infusion could effectively reduce the alarm delay when ASV was not used, and occlusion alarm delay was almost inversely proportional to the infusion rates. We have chosen to study these arrangements (IR10 and IR50), in order to simply compare the relationship between the infusion rates and the occlusion alarm delay, as well as to investigate the influence of combinations of different infusion rates on the prolongation of alarm delay. However, the infusion of intravenous agent to the proximal portion to ARV is not recommended in clinical setting, because the reflux of a potent drug into the fluid line has a risk for unidentified massive infusion after occlusion release.

Without ASV, combined infusions of fast and slow infusions into the same anticipating portion to be closed significantly prolonged alarm delay than a fast infusion alone. In this setup, when the slow infusion was added, the total compliance might be doubled, but the summation of infusion rates are not doubled. Accordingly, the prolongation of alarm delay during combined infusions of $10 \mathrm{ml} / \mathrm{h}$ and $50 \mathrm{ml} / \mathrm{h}$ could be anticipated. The degree of prolongation was estimated as $66.7 \%$ increase (see Appendix). Actually, the prolongation of the measured alarm delays was as much as $65.2 \%$ increase (81 to $133 \mathrm{~s}$ ). This prolongation could be expected to be more distinct, when slower infusion was added to the fast infusion. The examples in the Appendix shows that the more we added slower infusions, the more the occlusion alarms were delayed.

However, if we incorporate the ASV between each infusion system and the mainstream, the communication of the intrabarrel pressure between the infusion systems would be blocked. Thus, the increase of pressure of the faster infusion might be not transferred to the intra-barrel space of the slower infusion. As a result, the alarm delay of the fast infusion would not be prolonged. Meanwhile, in this setup, where the ASVs are un- 
available, ASV could be replaced with ARV, and yet alarm delay will not be prolonged, because ARV has the same function to prevent backflow. However, anti-syphon effect might not be guaranteed, but just expecting the incorporated anti-syphon function of the syringe pump itself.

Our result also showed that $\mathrm{T}_{\mathrm{m}}$ of IR10\&50 + ASV was shorter than $\mathrm{T}_{\mathrm{m}}$ of IR50, but statistically insignificant $(\mathrm{P}=0.403)$. In case of single infusions, ASV might be also considered to decrease alarm delay, because they are maintaining higher baseline driving pressures $\left(\mathrm{P}_{\max }, \mathrm{P}_{30 \min }\right.$, and $\left.\mathrm{P}_{0}\right)$ to push the fluid against the high crack pressure of ASV. Consequently, in isolated occlusion challenges at the distal portion of ASV, the results might be different to our multiple parallel infusion setups.

The estimated compliance of the infusion system might be the summation of those of the syringe and infusion line, as well as undetected air in the infusion system. The mean compliance of the infusion system, similar to that of our investigation, was reported as $1.33 \mu \mathrm{l} / \mathrm{mmHg}$ [6], which was nearly identical to our result. However, the previous authors investigated the compliance during low flow rate infusion $(1.0 \mathrm{ml} / \mathrm{h})$ and $230 \mathrm{mmHg}$ of alarm threshold, and monitored the intra-barrel pressure, instead of the syringe driving pressure, and the flushing volume after occlusion release, instead of the infusion rate.

For the post-hoc analysis, we proposed a method of calculation of the predicted time delay of occlusion alarm (Equation 1). The calculated prediction times using this equation were nearly identical to the measured alarm delays. The variables in this equation could be concluded as main factors relevant to alarm delay. As reported previously, highest possible infusion rate and smaller sized syringes are useful in decreasing alarm delays [7-9]. Routine use of a less compliant syringe and syringe extension line might be recommended to reduce the alarm delay $[6,10]$. During the infusion of drugs requiring a smaller amount of initial bolus, such as remifentanil, lowering the setting of occlusion alarm threshold $\left(\mathrm{P}_{\text {set }}\right)$ could decrease the alarm delay. However, the presence of air in a syringe can increase the compliance of the syringe [11] and could prolong the alarm delay. Therefore, careful preparation of the infusion assembly with the least air could reduce an alarm delay.

In this study, in order to standardize the comparison between with ASV and without ASV, in-line ARV and ASV were used rather than commercially ready-made multi-line connector. Most commercialized multi-line connectors including ARV and ASV have a typical arrangement feature, like the setup of IR10\&50 + ARV. But, it has a limitation to add multiple infusions, and there can be difficulties in priming the line of side port for ASV, after application to the patient. However, in-line type valves are free of these shortcomings and are considered to be suitable for complex connections.

In conclusion, the four kinds of archetypal infusion arrangements were evaluated to decrease an occlusion alarm delay, even though they were insufficient to represent all clinical infusion environments. However, further extended applications of our findings would be appropriate to predict occlusion alarm delay in various clinical setups. In addition, it would be helpful to assemble infusion systems that could rapidly trigger a warning with less alarm delay prior to the occurrence of potential complications.

\section{References}

1. Minto CF, Schnider TW, Egan TD, Youngs E, Lemmens HJ, Gambus PL, et al. Influence of age and gender on the pharmacokinetics and pharmacodynamics of remifentanil. I. Model development. Anesthesiology 1997; 86: 10-23.

2. Gepts E, Camu F, Cockshott ID, Douglas EJ. Disposition of propofol administered as constant rate intravenous infusions in humans. Anesth Analg 1987; 66: 1256-63.

3. Struys MM, De Smet T, Depoorter B, Versichelen LF, Mortier EP, Dumortier FJ, et al. Comparison of plasma compartment versus two methods for effect compartment--controlled target-controlled infusion for propofol. Anesthesiology 2000; 92: 399-406.

4. Neff T, Fischer J, Fehr S, Baenziger O, Weiss M. Start-up delays of infusion syringe pumps. Paediatr Anaesth 2001; 11: 561-5.

5. McCarroll C, McAtamney D, Taylor R. Alteration in flow delivery with antisyphon devices. Anaesthesia 2000; 55: 355-7.

6. Weiss M, Neff T, Gerber A, Fischer J. Impact of infusion line compliance on syringe pump performance. Paediatr Anaesth 2000; 10: 595-9.

7. Dönmez A, Araz C, Kayhan Z. Syringe pumps take too long to give occlusion alarm. Paediatr Anaesth 2005; 15: 293-6.

8. Schmidt N, Saez C, Seri I, Maturana A. Impact of syringe size on the performance of infusion pumps at low flow rates. Pediatr Crit Care Med 2010; 11: 282-6.

9. Weiss M, Fischer J, Neff T, Baenziger O. The effects of syringe plunger design on drug delivery during vertical displacement of syringe pumps. Anaesthesia 2000; 55: 1094-8.

10. Deckert D, Buerkle C, Neurauter A, Hamm P, Lindner KH, Wenzel V. The effects of multiple infusion line extensions on occlusion alarm function of an infusion pump. Anesth Analg 2009; 108: 518-20.

11. Schulz G, Fischer J, Neff T, Bänziger O, Weiss M. The effect of air within the infusion syringe on drug delivery of syringe pump infusion systems. Anaesthesist 2000; 49: 1018-23. 


\section{Appendix}

If slower infusions without anti-syphon valve be added to the portion anticipated to be closed after occlusion, like the setup IR10\&50 of this study, the occlusion alarm delay of $n$ multiple infusions $\left(\mathrm{T}_{\text {Multi }}\right)$ will be prolonged than that of the fast infusion alone $\left(\mathrm{T}_{\text {Fast }}\right)$. And the percentage increase of alarm delay can be derived from Equation 1, where $\mathrm{C}$ is compliance and IR is infusion rate, and will be calculated as follows;

$$
\text { Percentage increase }(\%)=100 \times \frac{T_{\text {Multi }}-T_{\text {Fast }}}{T_{\text {Fast }}}=100 \times \frac{\frac{\sum_{i=1}^{n} C_{i}}{\sum_{i=1}^{n} I R_{i}}-\frac{C_{\text {Fast }}}{I R_{\text {Fast }}}}{\frac{C_{\text {Fast }}}{I R_{\text {Fast }}}}
$$

When the compliances of all infusion system (syringe and line) are equal, the equation will be simplified as follows;

$$
\text { Percentage increase }(\%)=100 \times \frac{n \times I R_{\text {Fast }}-\sum_{i=1}^{n} I R_{i}}{\sum_{i=1}^{n} I R_{i}}
$$

For examples, if $50 \mathrm{ml} / \mathrm{h}, 10 \mathrm{ml} / \mathrm{h}$, and $5 \mathrm{ml} / \mathrm{h}$ be added to $50 \mathrm{ml} / \mathrm{h}$ infusion, the percentage increase of alarm delay will be;

(1) $50 \mathrm{ml} / \mathrm{h}$ to $50 \mathrm{ml} / \mathrm{h} ; 100 \times[2 \times 50-(50+50)] /(50+50)=0 \%$ increase

(2) $10 \mathrm{ml} / \mathrm{h}$ to $50 \mathrm{ml} / \mathrm{h} ; 100 \times[2 \times 50-(50+10)] /(50+10) \approx 67 \%$ increase

(3) $5 \mathrm{ml} / \mathrm{h}$ to $50 \mathrm{ml} / \mathrm{h} ; 100 \times[2 \times 50-(50+5)] /(50+5) \approx 82 \%$ increase

(4) $(5 \mathrm{ml} / \mathrm{h}+10 \mathrm{ml} / \mathrm{h})$ to $50 \mathrm{ml} / \mathrm{h} ; 100 \times[3 \times 50-(50+10+5)] /(50+10+5) \approx 131 \%$ increase 